\title{
INDICADORES SOCIAIS E POLÍTICAS PÚBLICAS DE ACESSIBILIDADE
}

\author{
Clovis Demarchi ${ }^{1}$ \\ Elaine Cristina Maieski ${ }^{2}$
}

Recebido em 14/12/2020

Aceito em 21/12/2020

\section{RESUMO}

$\mathrm{O}$ artigo tem como objetivo geral demonstrar a importância dos indicadores sociais como instrumentos para a elaboração, implementação e avaliação de políticas públicas, especialmente as relativas às pessoas com deficiência. Como objetivos específicos têm-se, entre outros: a) analisar se o Estatuto da Pessoa com Deficiência tem sido usado como referência na elaboração dos indicadores sociais sobre deficientes no Brasil; b) analisar se o Estatuto da Pessoa com Deficiência foi elaborado utilizando critérios de formação de indicadores sociais e se tem sido usado para a efetivação do direito a acessibilidade; c) analisar se Estatuto da Pessoa com Deficiência, se totalmente efetivado, atenderia as necessidades das pessoas com deficiência. Os indicadores sociais são matéria prima essencial no campo da elaboração, implementação e avaliação de políticas públicas e considerados os balizadores de programas que possibilitam o cumprimento dos direitos fundamentais. A identificação e a eliminação das barreiras - físicas e sociais, somente será possível com políticas públicas baseadas em indicadores sociais específicos. A acessibilidade em todos os níveis é o direito que garante à pessoa com deficiência ou com mobilidade reduzida viver de forma independente e exercer seus direitos de cidadania e de participação social. Quanto à metodologia, teve-se uma abordagem qualitativa e quantitativa, como técnica a pesquisa bibliográfica e documental.

PALAVRAS CHAVE: Políticas Públicas. Indicadores Sociais. Acessibilidade. Pessoa com Deficiência.

\section{SOCIAL INDICATORS AND ACCESSIBILITY PUBLIC POLICIES}

\section{ABSTRACT}

The general objective of the article is to demonstrate the importance of social indicators as instruments for the elaboration, implementation and evaluation of public policies, especially those related to people with disabilities. The specific objectives are, among others: a) to analyze whether the Statute for Persons with Disabilities has been used as a reference in the elaboration of social indicators on the disabled in Brazil; b) to analyze if the Statute of the Person with Disabilities was elaborated using criteria for the formation of social indicators and if it has been used for the realization of the right to accessibility; c) analyze whether the Disabled Person's Statute, if fully implemented, would meet the needs of people with disabilities. Social indicators are an essential raw material in the field of drafting, implementing and evaluating public policies, and are considered the

\footnotetext{
${ }^{1}$ Doutor e Mestre em Ciência Jurídica pela Universidade do Vale do Itajaí. Professor na graduação em Direito e no Programa de "Pós-graduação stricto Sensu" em Ciência Jurídica da Univali. Líder do grupo de pesquisa Governança, Constitucionalismo, Transnacionalidade e Sustentabilidade. Endereço eletrônico: demarchi@univali.br

${ }^{2}$ Jornalista. Bolsista de iniciação científica CNPq. Acadêmica do Curso de Direito da Escola de Ciências Jurídicas e Sociais da Universidade do Vale do Itajaí - Campus de Itajaí. Endereço eletrônico: lane.maieski@gmail.com
} 
beacons of programs that enable compliance with fundamental rights. The identification and elimination of barriers - physical and social, will only be possible with public policies based on specific social indicators. Accessibility at all levels is the right that guarantees people with disabilities or reduced mobility to live independently and exercise their citizenship and social participation rights. As for the methodology, there was a qualitative and quantitative approach, using bibliographic and documentary research as a technique.

Keywords: Public Policies. Social Indicators. Accessibility. Disabled Person.

\section{INTRODUÇÃO}

Ao iniciar o diálogo sobre os indicadores sociais, preliminarmente, se faz necessário entender a sua função na gestão pública e na vida do cidadão. Os indicadores sociais surgiram nos Estados Unidos na década de 1960, entretanto estão intrinsicamente ligados a estruturação do Estado e à consolidação das atividades de planejamento do setor público ao longo do século XX (JANNUZZI, 2017, p.13).

No Brasil, os indicadores sociais passaram a ser empregados como instrumento de planejamento governamental a partir da década de 1970 com a construção de um sistema de indicadores sociais e de produção periódica da informação, visando fornecer elementos para elaboração e acompanhamento do planejamento social. (SANTAGADA, 2007).

Os indicadores sociais são ferramentas efetivas de monitoramento da mudança social. Eles acompanham as transformações sociais e são usados para aferição da eficácia, ou não, das políticas sociais. O princípio da origem de um indicador está centrado em servir de instrumento para o planejamento governamental. Os indicadores sociais são matéria prima essencial no campo da elaboração, implementação e avaliação de políticas públicas. São considerados os balizadores de programas de inserção social que possibilitam o cumprimento dos direitos fundamentais (JANNUZZI, 2016, p. 47-52).

Neste viés, pretende-se no presente artigo, discutir sobre os indicadores sociais e a sua importância como subsídios na elaboração das políticas públicas que visam a efetivação de direitos, em especial, das pessoas com deficiência, bem como, analisar se o Estatuto da Pessoa com Deficiência (BRASIL, 2015) está sendo utilizado como parâmetro para a criação destes indicadores sociais.

Notadamente, o Estado somente atenderá a estas demandas com a implementação de políticas públicas adequadas às necessidades das pessoas com deficiência, principalmente na eliminação das barreiras - físicas e sociais - efetivando a acessibilidade da pessoa com deficiência, possibilitando que elas possam se realizar e se desenvolver livremente, criando, conforme Wloch e Demarchi (2015, p. 60), "ideias de igualdade e universalidade [...] que alcança legitimidade por meio dos esforços de criar uma nação homogênea por meio da unificação linguística, religiosa e cultural", 
entre outras.

É a elaboração de políticas públicas, com base em indicadores sociais construídos à partir das demandas específicas, que possibilita a construção de projetos inclusivos, tendo a acessibilidade como escopo, garantindo à pessoa com deficiência ou com mobilidade reduzida viver de forma independente, exercendo seus direitos de cidadania e de participação social.

Com a entrada em vigor do Estatuto da Pessoa com Deficiência, passou-se a discutir sob a ótica de um novo parâmetro de deficiência, baseado nos direitos humanos e voltado para a construção de um novo modelo de visão social, onde o próprio ambiente cria e influencia diretamente na liberdade da pessoa com deficiência, enfocando a implementação de políticas públicas, estratégias jurídicas e sociais que excluam os obstáculos e as discriminações, focadas na concretização da inclusão das pessoas deficientes, efetivando a acessibilidade da pessoa com deficiência, possibilitando que essas pessoas possam se realizar e se desenvolver livremente (SARMENTO, 2016, p. 241).

Portanto, o objetivo central da pesquisa, é analisar se o Estatuto da Pessoa com Deficiência tem sido usado como referência na elaboração dos indicadores sociais sobre deficientes no Brasil; analisar como são formados atualmente os indicadores sociais sobre deficientes no Brasil, se o Estatuto da Pessoa com Deficiência foi elaborado utilizando critérios de formação de indicadores sociais e se tem sido usado para a efetivação do direito a acessibilidade e ainda, se Estatuto da Pessoa com Deficiência, se totalmente efetivado, atenderia as necessidades das pessoas com deficiência.

Neste contexto, a criação de indicadores sociais especificamente criados a partir das reais demandas das pessoas com deficiência, identificarão as barreiras que ainda impedem a ampla inclusão e acessibilidade, possibilitando a implementação de políticas públicas eficazes.

Quanto à metodologia teve-se como base uma abordagem qualitativa e quantitativa, a técnica de pesquisa foi a análise bibliográfica e documental.

\section{ASPECTOS HISTÓRICOS E JURÍDICOS DAS POLÍTICAS PÚBLICAS}

As políticas públicas apresentam um entendimento pacificado que as define como metas coletivas, formadas por um conjunto de práticas e diretrizes que têm por objetivo a solução de problemas de interesse público. São desenvolvidas a partir dos indicadores sociais que identificam as necessidades dos grupos sociais e apontam os caminhos a serem trilhados para sua eficácia (JANNUZZI, 2017, p.151).

A implementação das políticas públicas é uma questão fundamental, pois elas estão intimamente ligadas à transformação da realidade. Toda a eficácia de uma determinada lei está atrelada à implementação de políticas públicas que torne real no cotidiano das pessoas todos os direitos nela 
tutelados pelo Estado. Sem políticas públicas a lei não será efetivamente aplicada (LIBERATI, 2012, p. 76).

$\mathrm{Na}$ formulação e execução das políticas públicas, a utilização dos princípios constitucionais - em especial da legalidade e do respeito à dignidade humana - desempenha função extraordinária, no sentido de assegurar, juridicamente, os direitos fundamentais posto no texto constitucional, que deverão ser implementados de acordo com a vontade do constituinte e do sistema jurídico vigente (MENDES; PAIVA, 2017. p. 101).

As políticas públicas podem ainda ser definidas como todas as ações de governo e podem variar de acordo com o grau de diversificação da economia, com a natureza do regime social, com a visão que os governantes têm do papel do Estado no conjunto da sociedade e com o nível de atuação dos diferentes grupos sociais, como partidos, associações de classe e outras formas de organização social.

Políticas públicas, portanto, são aquelas desenvolvidas por funcionários e organismos governamentais e possibilitam ao Estado a garantia do exercício dos direitos fundamentais individuais. Devem responder às necessidades e direitos das pessoas, que têm assegurada, no texto constitucional, a proteção da dignidade, da liberdade, da intimidade e de outros tantos direitos subjetivos individuais e coletivos (LIBERATI, 2012, p. 82).

Na visão de Monteiro (1991, p. 72) as políticas públicas podem ser consideradas como um fluxo de decisões que resulta, em última instancia, de um processo político, de cuja decisão participam diversos agentes políticos observadas as regras de natureza legal-institucionalconstitucional, sob as quais se definem os comportamentos desses agentes, suas escolhas, suas estratégias e, enfim, o resultado do jogo: a política pública.

Para entender como se dá a implementação das políticas públicas é necessário antes entender a influência constitucional nesse campo. A Constituição Brasileira de 1988 evidencia traços característicos que denotam sua filiação à tendência contemporânea do constitucionalismo inaugurada após a Primeira Guerra Mundial, marcada pela redefinição do papel e do âmbito material dos textos constitucionais. As Constituições modernas deixaram de se restringir à disciplina do político, de modo a alcançar também as esferas econômica e social. Essa tendência implica no abandono de um figurino constitucional voltado eminentemente à disciplina da organização política do Estado, aceitando o modelo econômico-social praticado no mundo real. É o que se denomina ampliação do "campo" constitucional. (MORAES, 2009, p. 74.)

Neste contexto ao dirigismo constitucional, conforme Canotilho, mediante a imposição de conjunto normativo definidor de metas, diretrizes, programas e tarefas em conformidade ao texto constitucional, caberia a missão de apontar soluções e linhas de ação política de modo a responder a 
demandas sociais e econômicas nas áreas de saúde, educação, lazer e trabalho, entre outras, mobilizando governantes e legisladores a concretizar o programa ou plano constitucional.

O dirigismo constitucional caracteriza-se pela definição, a nível constitucional, de tarefas econômicas e sociais do Estado, direcionando a atuação dos poderes políticos e a consecução de políticas públicas (CANOTILHO, 1994, p.169.). Cuida-se, portanto, da instituição de um programa político-constitucional obrigatório que orienta a intervenção do Estado no domínio econômico social.

Deste modo, o Estado assume uma função de extrema relevância, que não se limita a aspectos formais, mas com o conteúdo dos direitos garantidos, consistindo em assegurar uma convivência pacífica e harmoniosa mediante a garantia de Direitos Fundamentais para sujeitos culturalmente diferentes. [...] O cerne da questão não é o de reconhecer direitos, mas o de garanti-los. (DEMARCHI; COELHO, 2018, p 194)

Para Santos (2006, p. 219) as políticas públicas surgiram no contexto do Estado Social “cujo fundamento se assenta na existência dos direitos sociais constitucionalmente positivados e se dá por meio de prestações positivas do Estado".

Loewenstein (1986. p. 401) lembra que esses direitos socioeconômicos não são absolutamente novos, sendo que alguns deles, como o direito ao trabalho, já haviam sido reconhecidos na Constituição Francesa de 1723 e 1848. Todavia, somente no século XX se converteram no conteúdo do constitucionalismo após a Segunda Guerra. Foram assim, proclamados pela primeira vez na Constituição Mexicana de 1917 que nacionalizou todas as riquezas naturais e encarregou o Estado da responsabilidade social de garantir uma existência digna a cada um de seus cidadãos. Contudo, foi a Constituição de Weimar a que mais contribuiu para popularizar e estender os direitos sociais.

Enquanto no individualismo, que se fortaleceu na superação da monarquia absolutista, o Estado era considerado o inimigo contra o qual se deveria proteger a liberdade do indivíduo, com a filosofia social o Estado se converteu em amigo, obrigado que estava, a partir de então, a satisfazer as necessidades coletivas da comunidade (TAVARES, 2017, p.357).

Neste contexto, observa-se a influência das tratativas de direitos em termos globais que, segundo Demarchi (2019, p. 38), "no aspecto político, isto é, de nação, com base no cidadão [...] subverte esta ordem ao considerar os princípios e fundamentos que são gerais como, por exemplo, a segurança, o meio ambiente, direitos humanos e redução da violência em necessidades humanas globais".

No relato de Bucci (2002, p. 252) as políticas públicas evoluíram no sentido formal, assim como esta foi uma evolução em relação ao constitucionalismo. Desta forma, entende-se que o aspecto funcional inovador de qualquer modelo de estruturação do poder político caberá às políticas públicas.

A função de governar por políticas públicas não exclui, e jamais poderá excluir, o respeito 
à legalidade. Entre a lei e as políticas públicas, deve haver uma simbiose e estas devem ser incorporadas ao comando constitucional, e das leis ordinárias, afirmando que tais políticas passam a ser reconhecidas pelo Direito e a gerar efeitos jurídicos em todo o conjunto de atos e omissões que constituem cada política (BUCCI, 2002, p. 255).

A política pública não é lei e não se confunde com ela, mas ambas convivem e se completam. As políticas públicas constituem um meio de concretização dos direitos que estão codificados nas leis de um país. Nesse sentido, a Constituição não contém políticas públicas, mas, direitos cuja efetivação se dá por meio de políticas públicas, cujo catalogo constará dos textos legais e, principalmente, da Constituição, oferecendo garantia e segurança jurídica à população (LIBERATI, 2012, p. 95).

Assim, uma política pública pode tanto ser parte de uma política de Estado ou uma política de governo. Considera-se que políticas de governo são aquelas que o Executivo decide num processo elementar de formulação e implementação de determinadas medidas e programas, visando responder às demandas da agenda política interna, ainda que envolvam escolhas complexas. Já as políticas de Estado são aquelas que envolvem mais de uma agência do Estado, passando em geral pelo Parlamento ou por instâncias diversas de discussão, resultando em mudanças de outras normas ou disposições preexistentes, com incidência em setores mais amplos da sociedade (BOITO JUNIOR, 2007, p. 106108).

Neste sentido, pode-se entender o processo de formulação de políticas públicas como uma sucessão de negociações identificado por meio dos mais diversos mecanismos de participação social e demandas dos grupos sociais.

A intervenção, via política pública, numa determinada área não deve ser uma decisão solitária e limitada tão somente a quem detém o poder político momentaneamente. A participação da sociedade deve ser considerada de fundamental importância para a implantação e implementação de políticas que atendam as reais necessidades da população e estabeleçam seus limites e alcances (DIAS, MATOS, 2012, p. 61.).

Rodrigues (2010, p. 25) lembra que para as políticas públicas se efetivarem, há uma condição fundamental, que é a capacidade de intervenção dos diversos atores políticos envolvidos no processo.

As transformações propiciadas pelas políticas públicas só serão possíveis se os agentes demonstrarem capacidade não só para diagnosticar e analisar a realidade social, econômica e política em que vivem, mas também para interagir e negociar de forma democrática com os diferentes atores envolvidos no processo.

Contexto no qual analisa-se a Lei Brasileira de Inclusão (LBI), Lei 13.146 de 2015, 
também conhecida como Estatuto da Pessoa com Deficiência, considerada como um grande avanço e que impacta diretamente a vida de cerca de 45 milhões de brasileiros com algum grau de deficiência e, indiretamente, toda sociedade, governo e instituições, muito embora ainda não esteja sendo utilizada como ferramenta efetiva na elaboração das políticas públicas para as pessoas com deficiência.

Destaca-se que a lei alterou o instituto da capacidade possibilitando que a pessoa deficiente possa exercer atos da vida civil, como o direito de casar e exercer direitos reprodutivos em igualdade de condições com as demais pessoas. Introduziu novos institutos como a Tomada de Decisão Apoiada. Assegurou a oferta de sistema educacional em todos os níveis e modalidades de ensino. Criou benefício assistencial para o ingresso no mercado de trabalho e incluiu o desrespeito às normas de acessibilidade como causa de improbidade administrativa (DEMARCHI; MAIESKI, 2019, p. 107) e, embora provoque o Estado e a sociedade para o cumprimento de metas inclusivas, ainda tem sido muito pouco utilizado, tendo sua eficácia bastante reduzida.

\section{PESSOA COM DEFICIÊNCIA E ACESSIBILIDADE}

Em conceito amplo a acessibilidade pode ser definida como a qualidade do que é acessível, algo atingível e de acesso fácil à qualquer pessoa. Está intrinsecamente ligada a possibilidade de fornecer condições às pessoas com deficiência ou com mobilidade reduzida, para a utilização de forma segura e autônoma, dos espaços privados, públicos, individuais e coletivos.

Segundo conceitua o Estatuto da Pessoa com Deficiência (BRASIL, 2015), acessibilidade é a possibilidade e a condição de alcance para utilização, com segurança e autonomia, de espaços, mobiliários, equipamentos, edificações, transportes, informação e comunicação, inclusive de sistemas e tecnologias, por pessoa com deficiência ou com mobilidade reduzida, como forma de não discriminação, garantindo a inclusão e a promoção à dignidade humana, a liberdade e ao acesso aos direitos fundamentais.

A acessibilidade nem sempre foi concebida de forma não discriminativa. $\mathrm{O}$ conceito de acessibilidade vem sofrendo alterações e evoluindo, principalmente por imposições da legislação, ao longo dos anos. Até bem pouco tempo, a definição de acessibilidade tinha relação estreita com o conceito de deficiência, e estava basicamente relacionada a adequação de estruturas às pessoas com deficiência.

Conforme Barcellos e Campante (2012), a deficiência foi compreendida, durante muito tempo, como condição medica e a acessibilidade como uma consequente adaptação do meio aos déficits de natureza física, mental ou cognitivas, que até então, caracterizavam as pessoas com deficiência. A organização da sociedade partia do princípio de que a pessoa com deficiência é que 
necessitava de assistência "em função da sua inadequação aos meios usuais de acesso aos direitos e aos bens da vida social em geral e, a acessibilidade era a ferramenta por meio da qual a sociedade respondia às necessidades excepcionais da pessoa com deficiência".

A Convenção Internacional sobre os Direitos das Pessoas com Deficiência (ONU, 2006) define como pessoas com deficiência "aquelas que têm impedimentos de longo prazo de natureza física, mental, intelectual ou sensorial, os quais, em interação com diversas barreiras, podem obstruir sua participação plena e efetiva na sociedade em igualdades de condições com as demais pessoas".

A discriminação por motivo de deficiência significa qualquer diferenciação, exclusão ou restrição baseada na deficiência da pessoa "com o propósito ou efeito de impedir ou impossibilitar o reconhecimento, o desfrute ou o exercício, em igualdade de oportunidades com as demais pessoas, de todos os direitos humanos e liberdades fundamentais nos âmbitos político, econômico, social, cultural, civil ou qualquer outro" e tais práticas de discriminação, abrangem inclusive a acessibilidade e a recusa de adaptação razoável.

A própria legislação conceitua adaptação razoável (BRASIL, 2009) como as modificações e os ajustes necessários e adequados que não acarretem ônus desproporcional ou indevido, quando requeridos em cada caso, a fim de assegurar que as pessoas com deficiência possam gozar ou exercer, em igualdade de oportunidades com as demais pessoas, todos os direitos humanos e liberdades fundamentais

Neste contexto, a acessibilidade é revelada como princípio fundamental, principalmente para que as pessoas com deficiência possam concretizar seus direitos fundamentais, em todos os aspectos de suas vidas.

Para Lopes (2009, p. 140-141), a acessibilidade é um direito natural, inato ao ser humano. "Assegura-se legitimidade e a implantação da acessibilidade como princípio norteador dos sistemas jurídicos e como um direito fundamental". Desta forma, de acordo com o raciocínio da autora, sendo considerado um princípio-direito "obriga os Estados à sua implementação como garantia fundamental, extremamente relevante para a concretização dos direitos humanos das pessoas com deficiência".

A Convenção sobre os Direitos da Pessoa com Deficiência (ONU, 2006), se refere à acessibilidade como ferramenta para que as pessoas com deficiência atinjam sua autonomia em todos os aspectos da vida, o que demonstra uma visão atualizada das especificidades destas pessoas, que buscam participar dos meios mais usuais que a sociedade em geral utiliza para funcionar plenamente nos dias de hoje, não se reduzindo apenas à acessibilidade ao meio físico (VITAL, 2008, p. 44).

A acessibilidade ao meio físico promove a inclusão e é primordial para que direitos fundamentais sejam resguardados, dando aos deficientes a oportunidade de exercer a sua cidadania. Toda ação que possibilite acesso de pessoas com deficiência aos serviços de transportes, equipamentos 
urbanos e a circulação em áreas públicas, entre outros, são basicamente a efetivação da dignidade humana. Entretanto, não é apenas a acessibilidade ao meio físico que imprime pertinente discussão. Tal qual acesso à lugares físicos, o acesso a informação, à educação, a arte e cultura são tão fundamentais e urgente quanto ao direito de ir e vir.

O Estatuto da Pessoa com Deficiência (BRASIL, 2015) discute inserção sob a ótica de um novo parâmetro de deficiência, baseado nos direitos humanos e voltado para a construção de um novo modelo de visão social, onde o próprio ambiente cria e influencia diretamente na liberdade da pessoa com deficiência, enfocando a implementação de políticas públicas, estratégias jurídicas e sociais que excluam os obstáculos e as discriminações, focadas na efetivação da inclusão das pessoas deficientes, especialmente na eliminação das barreiras - físicas e sociais, efetivando a acessibilidade da pessoa com deficiência, possibilitando que essas pessoas possam se realizar e se desenvolver livremente (SARMENTO, 2016, p 241).

O Artigo $3^{\circ}$ da Lei 13.146/15 (BRASIL, 2015), especifica que acessibilidade é a possibilidade e a condição de alcance para utilização, com segurança e autonomia, de espaços, mobiliários, equipamentos urbanos, edificações, transportes, informação e comunicação, inclusive seus sistemas e tecnologias, bem como de outros serviços e instalações abertos ao público, de uso público ou privados de uso coletivo, tanto na zona urbana como na rural, por pessoa com deficiência ou com mobilidade reduzida.

Já o art. 53 do Estatuto consolida a acessibilidade como princípio e direito humano fundamental: "A acessibilidade é direito que garante à pessoa com deficiência ou com mobilidade reduzida viver de forma independente e exercer seus direitos de cidadania e de participação social".

Vê-se, portanto, que a acessibilidade é intrínseca à dignidade humana, é um direito que garante à pessoa com deficiência viver de forma mais digna, independente, exercendo com total plenitude seus direitos de cidadania e de participação social.

Com entendimento doutrinário pacificado, a acessibilidade é um dos principais objetivos do Estatuto da Pessoa com Deficiência, visto que, ao estabelecer as regras para aplicação da lei, define a eliminação das barreiras, tanto físicas quanto sociais, como "meio para a acessibilidade, garantindo os direitos considerados fundamentais, sem os quais a pessoa humana não pode existir ou não é capaz de se desenvolver e de participar plenamente da vida", como bem define Dallari (2004, p. 98).

Nesse sentido, apresentam-se algumas políticas para acessibilidade dos deficientes em alguns setores, com destaque nas áreas da educação e saúde, entretanto, é importante observar que em outros setores ainda há muito a ser construído e, a forma como essas políticas públicas são elaboradas e implementadas, merecem especial destaque, especialmente com o estudo dos indicadores sociais.

A discriminação sofrida pelas pessoas com deficiência de certo modo foi corrigida com o 
advento na nova Lei, que estabeleceu em seu texto legal a proteção da pessoa com deficiência de qualquer forma de discriminação (PINTO, 2016, p. 32). Porém, um longo caminho ainda se faz necessário para efetivação destes direitos, perpassando a criação de indicadores sociais específicos e a implementação de políticas públicas voltadas às reais demandas deste grupo.

Observa-se a existência de um vácuo prestacional por parte do Estado, que não tem garantido de forma eficiente a acessibilidade à pessoa com deficiência e a constatação está intrinsicamente ligada à falta de políticas públicas destinadas a tal propósito, visto que as ferramentas utilizadas para obter dados concretos da população ainda se mostram bastante acanhadas, incluindo o Censo Demográfico 2020, como veremos a seguir.

\section{INDICADORES SOCIAIS E A PESSOA COM DEFICIÊNCIA}

O princípio inicial da origem do indicador está centrado em servir de instrumento para o planejamento governamental. Os indicadores sociais são subsídios essenciais no campo da elaboração e avaliação de políticas públicas.

Para Jannuzzi (2017, p. 47), um Indicador Social é considerado uma medida em geral quantitativa, capaz de substituir ou quantificar um conceito social abstrato. É, portanto, um recurso metodológico empírico, pois informa algo sobre a realidade social ou sobre as mudanças que estão em processo.

Desde sua origem, os indicadores sociais fazem parte de um contexto socioeconômico amplo e devem trazer respostas para as preocupações referentes à dinâmica social (JANNUZZI, 2016, p. 45). Portanto, cabe aos indicadores elucidarem questões que vão além da informação quantitativa, aproximando-se ao máximo da realidade social. (SANTAGADA, 2007).

Historicamente, a partir de 1966, surgiu a primeira ocorrência da expressão “indicadores sociais", na obra de Bauer (1968), nos EUA. Na ocasião, a análise econômica - representada pelo Produto Interno Bruto (PIB) - não explicava a disparidade entre o crescimento econômico e os conflitos sociais da época. O Estado, então, é visto como árbitro do bem comum.

A década de 1970 foi marcada pelo crescimento e elaboração dos indicadores sociais por organismos internacionais. Santagada (2007) relata a adesão dos organismos internacionais no esforço de estudar os indicadores sociais comparando as condições de vida da população entre diferentes países. Entre estes organismo estava a Organização das Nações Unidas (ONU), a Cooperação e Desenvolvimento Econômico (OCDE), o Banco Mundial e o Programa das Nações Unidas para o Desenvolvimento (PNUD). 
Em contrapartida, nos anos 1980 se viveu um certo desprezo pelos indicadores sociais, marcado pela crise fiscal e a visão de um Estado mínimo adotada principalmente na Inglaterra e nos EUA. Já a retomada da importância dos indicadores se deu somente na década 1990, quando ganharam destaque novos temas sobre desigualdade social, qualidade de vida, direitos humanos, liberdades políticas, desenvolvimento sustentável e responsabilidade social - temas centrais na pauta de governo de vários países (BRASIL, 2010).

Apesar de ter ganho corpo técnico cientifico nos anos de 1960, na fluorescente organização dos sistemas de acompanhamento das transformações sociais, há registros de contribuições anteriores na construção do marco conceitual sobre indicadores sociais. Neste viés, Jannuzzi (2017, p. 17) destacada que estudos do sociólogo Emile Durkhein nas primeiras décadas do século passado, ou até antes, apontam que "embora o termo "indicador social" passasse a ser dominante nos anos de 1960, a "estatística" como prática de qualificação de fenômenos sociais para tomada de decisão pública remonta ao século XVII.

No Brasil, os indicadores sociais passaram a ser empregados como instrumento de planejamento governamental na década de 1970. Em 1973 foi criado no IBGE - Instituto Brasileiro de Geografia e Estatística um grupo de trabalho multidisciplinar para estruturar um sistema de indicadores sociais que pudesse orientar a pesquisa e publicações de campo (JANNUZZI, 2017, p. 19).

Em 1974, foi criado o Conselho de Desenvolvimento Social (CDS). Esse conselho, em 1975, propôs a construção de um sistema de indicadores sociais e de produção periódica da informação, visando fornecer elementos para elaboração e acompanhamento do planejamento social. (SANTAGADA, 2007).

Nos últimos 30 anos, houve um aumento no interesse pelo uso de indicadores na administração pública brasileira. Para Jannuzzi (2017, p. 24) essa elevação está relacionada ao aprimoramento do controle social do Estado. As novas tecnologias da informação e comunicação também desempenham um importante papel ao viabilizarem o acesso às informações de natureza estatística e administrativa (JANNUZZI, 2005).

Enquanto instrumentos operacionais, os indicadores permitem identificar e medir aspectos relacionados ao resultado de uma intervenção na realidade. Segundo o Ministério do Planejamento, Orçamento e Gestão, os indicadores possuem duas funções básicas: descritiva: a que retrata uma realidade empírica, situação social ou ação pública, a exemplo da quantidade de famílias em situação de pobreza; e valorativa: que acrescenta informação de juízo de valor à uma determinada situação, almejando avaliar a importância relativa de um problema em foco (BRASIL, 2010).

No processo de construção de um Sistema de Indicadores Sociais, a quantidade de indicadores vai depender do foco do objetivo estipulado, bem como da disponibilidade de dados e de 
estatísticas que atendam à demanda programática.

Jannuzzi (2017, p. 96) chama a atenção para uma importante diferença entre indicadores sociais e estatísticas públicas. Estatísticas Públicas correspondem ao dado social em sua forma bruta, parcialmente preparado para a interpretação empírica da realidade. No entanto, as estatísticas públicas não estão inteiramente contextualizadas em uma teoria social. Elas se constituem na matéria-prima para a construção de indicadores sociais.

Ponto de relevância é destacar que hoje no Brasil, verifica-se a construção majoritária de estatísticas públicas, estando a formação de indicadores sociais específicos numa escala bem menor ou quase inexistente para determinados setores e grupos sociais.

No que tange a construção de indicadores específicos para demandas das pessoas com deficiência, constata-se uma reduzida preocupação com os indicadores sociais baseados nas diretrizes do Estatuto da Pessoa com Deficiência (BRASIL, 2015) e a falta de implementação de políticas públicas que efetivam os direitos dos deficientes no Brasil está apresentando como consequências a ineficiência da gestão pública nesta área, visto que não possui dados suficientes para elaboração de programas e uma correta aplicação dos recursos disponíveis na área.

A coleta de dados no Brasil, subsidio para criação de estatísticas públicas e indicadores sociais está diretamente ligada às pesquisas estatísticas realizadas pelo IBGE, com destaque para o Censo Demográfico realizado a cada dez anos. Em virtude da pandemia de Covid-19, a contagem populacional que haveria por meio do Censo 2020 foi adiada para 2021, quando serão visitados cerca de 71 milhões de domicílios em todo o território nacional (BRASIL, 2019a).

Importante destacar que o Governo Federal recuou na decisão de ampliação do Censo Demográfico brasileiro e, na contramão das demais Nações, reduziu o questionário básico, que vai contar com 25 questões, nove a menos que em 2010, e também o questionário da amostra, maior e aplicado em 10\% dos lares, que terá 76 questões, 26 a menos que em 2010 (BRASIL, 2019b).

A redução no número de questões, especialmente no questionário por amostragem, expõe a fragilidade do sistema de construção de indicadores sociais no Brasil, visto que é por meio destes indicativos que o país poderia criar indicadores específicos, de um número maior de grupos, incluindo o grupo das pessoas com deficiência.

De acordo com o IBGE, os questionários abarcam perguntas que irão formar características dos domicílios, identificação étnico-racial, nupcialidade, núcleo familiar, fecundidade, religião ou culto, deficiência, migração interna ou internacional, educação, deslocamento para estudo, trabalho e rendimento, deslocamento para trabalho, mortalidade (BRASIL, 2019c).

Nota-se que a categoria deficiência aparece de forma genérica, ou seja, o Censo 2020 irá apenas contar quantos são as pessoas com deficiência no Brasil, apontando, igualmente de forma 
genérica, se a deficiência é física ou mental. Não teremos, portanto, a criação de indicadores sociais que nos aponte qual é especificamente a deficiência, quais são as limitações e necessidades dos cidadãos brasileiros com deficiência e, por consequência, continuaremos sem perspectivas para implementação de políticas públicas condizentes com as demandas desta população.

Desta forma, o Brasil continua criando estatísticas públicas, por meio de perguntas genéricas, muito longe de garantir a efetivação paritária dos direitos das pessoas com deficiência, por meio dos indicadores sociais e políticas públicas direcionadas.

Constata-se, portanto, que o Estatuto da Pessoa com Deficiência, mesmo sendo um importante instrumento de efetivação da dignidade humana, facilitador para a implementação de políticas públicas voltadas às necessidades da pessoa com deficiência, está sendo minimizado, tendo a sua eficácia reduzida, deixando de ser o elemento primordial para eliminação das barreiras que ainda impedem ampla inclusão e acessibilidade da pessoa com deficiência (DEMARCHI; MAIESKI, 2019, p. 107).

Conforme revela Jannuzzi (2002, p. 51), não se deve superestimar o papel dos indicadores sociais em um ciclo de política pública. Especialmente nas fases de formulação e implementação, devese ter um cuidado especial, visto que estas dependem exclusivamente da qualidade da informação.

A construção de um sistema de indicadores é básica e fundamental. Para que haja o monitoramento e a avaliação de resultados na gestão pública é imprescindível que os governos utilizem processos estruturados e instrumentos críveis capazes de aferir os resultados da ação governamental com exatidão (JANNUZZI, 2016, p. 97).

A ineficiência do sistema pode residir justamente no uso inadequado das ferramentas para a elaboração das políticas públicas, ou seja, os atores responsáveis pelas políticas no Brasil podem não estar levando em consideração as regras básicas que constituem os ciclos do processo que envolvem o planejamento, a elaboração, a implementação e os resultados das políticas públicas, perpassando a criação dos indicadores sociais.

Sendo o IBGE o órgão oficial e praticamente exclusivo de coleta de dados no Brasil, a redução do questionário do Censo 2020, a falta de percepção social na coleta de dados e a consequente ausência de indicadores sociais, podem tornar ainda mais frágil o sistema de políticas públicas voltadas a grupos vulneráveis, podendo levar o país a um colapso social e econômico, expondo e sacrificando exponencialmente os cidadãos que mais necessitam de amparo estatal, especialmente, as pessoas com deficiência. 


\section{CONSIDERAÇÕES FINAIS}

Diante o exposto, observa-se que a reduzida preocupação com os indicadores sociais na fase de planejamento e, posteriormente, na implementação de políticas públicas que efetivam os direitos das pessoas com deficiência no Brasil tem como consequência grave a perda de recursos e a ineficiência da gestão pública que não possui dados suficientes para garantir a inclusão da pessoa com deficiência.

O Estatuto da Pessoa com Deficiência discute inserção sob a ótica de um novo parâmetro de deficiência, baseado nos direitos humanos e voltado para a construção de um novo modelo de visão social.

A lei alterou o instituto da capacidade possibilitando que a pessoa deficiente possa exercer atos da vida civil, como o direito de casar e exercer direitos reprodutivos em igualdade de condições com as demais pessoas. Introduziu novos institutos como a Tomada de Decisão Apoiada. Assegurou a oferta de sistema educacional em todos os níveis e modalidades de ensino. Criou benefício assistencial para o ingresso no mercado de trabalho e incluiu o desrespeito às normas de acessibilidade como causa de improbidade administrativa e, embora provoque o Estado e a sociedade para o cumprimento de metas inclusivas, ainda tem sido muito pouco utilizado, tendo sua eficácia bastante reduzida.

Constata-se que, apesar de ter um dos institutos estatísticos mais modernos do mundo, o Brasil não tem avançado na construção de indicadores sociais específicos e não tem identificado as reais demandas dos mais diversos grupos sociais integrantes da sua população.

Muito embora o censo brasileiro seja considerado um dos mais detalhados internacionalmente, sendo uma fonte quase exclusiva de informação para planejamento e para formulação de políticas públicas ainda se mostra focado majoritariamente em estatísticas públicas econômicas, educacionais, na área da saúde, trabalho, emprego e renda deixando de lado grupos especialmente fragilizados, como é o caso das pessoas com deficiência.

Quando se considera majoritariamente a estatística pública, em detrimento de indicadores sociais, dando maior atenção a alguns setores instala-se um desiquilibro prestacional por parte do estado, e as políticas públicas deixam de ser equânimes, ferindo inclusive os preceitos constitucionais.

Ao analisar o Estatuto da Pessoa com Deficiência observa-se que o mesmo não tem sido usado como referência na elaboração dos indicadores sociais sobre deficientes no Brasil. Conclui-se que a chamada Lei da Inclusão ainda não decolou no campo da construção de indicadores sociais específicos sobre os deficientes brasileiros.

Constata-se ainda que os indicadores sociais específicos sobre deficientes no Brasil 
praticamente inexistem, visto que atualmente os deficientes são contados de forma genérica. Criando assim apenas estatísticas amplas e que não há a identificação de todas as barreiras físicas e sociais, muito menos um detalhamento das reais demandas envolvendo as pessoas com deficiência no Brasil. Portanto, se inexistem indicadores determinando as demandas sociais, recursos públicos que poderiam estar sendo melhor destinados, podem estar se perdendo em políticas públicas equivocadas e sem nenhum resultado efetivo.

A análise verifica que processo de implementação de políticas públicas para as pessoas com deficiência pode estar tendo etapas fundamentais ceifadas, seja por despreparo técnico dos atores envolvidos ou ainda, por direcionamento inadequado das políticas públicas. Não raro, em muitos municípios brasileiros, pode-se observar, por exemplo, a destinação de investimentos em piso tátil para deficientes visuais, enquanto a demanda pode estar apontando para a necessidade de programas direcionados a deficientes auditivos com a disponibilização de áudio livros nas instituições públicas e nas escolas.

Conclui-se, neste contexto, que o Estatuto da Pessoa com Deficiência foi elaborado com base em diretrizes internacionais, bem como, adequações de leis brasileiras criadas ao longo dos tempos. Apesar de estar alinhado com a Constituição brasileira e atender os preceitos legais que uma lei exige, o Estatuto da Pessoa com Deficiência foi criado sem considerar os indicadores sociais sobre pessoas com deficiência, dada a incoerência que afirmação contraria apresentaria, uma vez que praticamente inexistem tais indicadores específicos no Brasil.

Entretanto, é imperioso lembrar que a utilização do Estatuto da Pessoa com Deficiência, deve ser referência na elaboração de critérios para a construção dos indicadores sociais sobre deficientes no Brasil. A total efetivação desta lei pode atender as necessidades das pessoas com deficiência no Brasil, pois atualmente se desconhece minuciosamente quantas são e, principalmente, quais são as demandas das pessoas com deficiência.

Os questionamentos levantados e as possíveis respostas apresentadas na presente pesquisa pretendem propor uma análise sobre o assunto, questionando sobre as prioridades e foco dos gestores públicos no que tange a criação de indicadores sociais reais e, consequente, a implementação de políticas públicas que respondam às demandas das pessoas com deficiência.

$\mathrm{O}$ assunto não se esgota com as constatações apresentadas. Pelo contrário, abre-se para uma nova discussão sobre o que se pretende para o futuro das pessoas com deficiência no Brasil e a responsabilidade do Estado e da sociedade. 


\section{REFERÊNCIAS BIBLIOGRÁFICAS}

BARCELLOS, Ana Paula de; CAMPANTE, Renata Ramos. A acessibilidade como instrumento de promoção de Direitos Fundamentais. Manual dos direitos da pessoa com deficiência. São Paulo: Saraiva, 2012. n.p. disponível em:

https://app.saraivadigital.com.br/leitor/ebook:582916. Acesso em: 05 out. 2019.

BAUER, Raymond A. Social Indicators. The University of Chicago Press Journals. American Journal of Sociology, no. 3, v. 74, nov.1968, p. 306-307. Disponível em: < https://www.journals.uchicago.edu/doi/10.1086/224646>. Acessado em 05 out. 2019.

BOITO JUNIOR, Armando. Estado, política e classes sociais: ensaios teóricos e históricos. São Paulo: Editora Unesp, 2007,

BRASIL. Agencia IBGE Notícias. Censo é adiado para 2021; coleta presencial de pesquisas é suspensa. Disponível em: https://agenciadenoticias.ibge.gov.br/agencianoticias/2012-agencia-de-noticias/noticias/27160-censo-e-adiado-para-2021-coletapresencial-de-pesquisas-e-suspensa.2019a.

BRASIL. Agencia IBGE Notícias. Com questionário definido, conheça as perguntas que serão feitas no Censo 2020. Disponível em: https://agenciadenoticias.ibge.gov.br/agencianoticias/2012-agencia-de-noticias/noticias/24914-com-questionario-definido-conheca-asperguntas-que-serao-feitas-no-censo-2020. 2019c.

BRASIL. Agencia IBGE Notícias. IBGE define tamanho dos questionários do Censo 2020. Disponível em: https://agenciadenoticias.ibge.gov.br/agencia-noticias.html. 2019b.

BRASIL. Decreto $n^{\circ}$ 6.949, de 25 de agosto de 2009. Promulga a Convenção Internacional sobre os Direitos das Pessoas com Deficiência e seu Protocolo Facultativo, assinados em Nova York, em 30 de março de 2007. Disponível em:

http://www.planalto.gov.br/ccivil_03/_ato2015-2018/2015/lei/113146.htm.

BRASIL. Lei 13.146 de 06 de julho de 2015. Institui a Lei Brasileira de Inclusão da Pessoa com Deficiência (Estatuto da Pessoa com Deficiência). Disponível em:

http://www.planalto.gov.br/ccivil_03/_ato2015-2018/2015/lei/113146.htm.

BRASIL. Ministério do planejamento, orçamento e gestão. Indicadores de programas: guia metodológico. Brasília, 2010. Disponível em:<

http://www.planejamento.gov.br/assuntos/projetos-encerrados/projeto-de-integracao-para-aeficiencia-da-gestao/guia-de-indicadores-dos-programas $>$.

BUCCI, Maria Paula Dallari. Direito administrativo e políticas públicas. São Paulo: Saraiva, 2002.

CANOTILHO, José Joaquim Gomes. A constituição dirigente e a vinculação do legislador: contributo para a compreensão das normas constitucionais programáticas. Coimbra: Coimbra Editora, reimpressão, 1994.

DALLARI, Dalmo de Abreu. Direitos humanos e cidadania. São Paulo: Moderna, 2004.

DEMARCHI, C.; COELHO, L. de C. P. A efetividade do direito fundamental à educação e a função social do estado. Rev. Ciênc. Juríd. Soc. UNIPAR. Umuarama. v. 21, n. 2, p. 185- 
199, jul./dez. 2018. Disponível em:

https://revistas.unipar.br/index.php/juridica/article/view/7501.

DEMARCHI, Clovis. Crise do estado e da democracia no contexto da globalização. Revista Jurídicas, Manizales, Colômbia, 16 (2), 29-44. 2019. Disponível em: http://juridicas.ucaldas.edu.co/downloads/Juridicas16(2)_3.pdf

DEMARCHI, Clovis; MAIESKI, Elaine Cristina. Alterações Legislativas para a efetivação do Estatuto da Pessoa com Deficiência e implementação de Políticas Públicas. Anais do II Congresso Internacional de Políticas Públicas para a América Latina: Direito, Saúde, Educação e Meio Ambiente. Itajaí, 2019. v. 5. Disponível em:

https://siaiap32.univali.br/seer/index.php/aemv/article/view/15619/8879

DIAS, Reinaldo; MATOS, Fernanda. Políticas Públicas. Princípios, propósitos e processos. São Paulo: Atlas, 2012.

JANNUZZI, Paulo de Martino. Considerações sobre o uso, mal uso e abuso dos indicadores sociais na formulação de políticas públicas municipais. Revista de Administração Pública. Rio de Janeiro, v. 36, n. 1, p. 51-72, jan/fev. 2002.

JANNUZZI, Paulo de Martino. Indicadores para diagnósticos, monitoramento e avaliação de programas sociais no Brasil. Revista do Serviço Público. Brasília, n. 2 v. 56, p.137-160, abr/jun. 2005.

JANNUZZI, Paulo de Martino. Indicadores Sociais no Brasil. Conceitos, fontes de dados e aplicações. 6 ed. São Paulo: Alínea, 2017.

JANNUZZI, Paulo de Martino. Monitoramento e Avaliação de Programas Sociais. Uma introdução aos conceitos e técnicas. São Paulo: Alínea: 2016.

LIBERATI, Wilson Donizeti. Políticas Públicas no Estado Constitucional. São Paulo: Editora Atlas, 2012.

LOEWENSTEISN, Karl. Teoria de la Constitución. Barcelona: Editora Ariel, 1986.

LOPES, Laís Vanessa Carvalho de Figueiredo. Convenção sobre os direitos das pessoas com deficiência da ONU e seu protocolo facultativo e a acessibilidade. Dissertação de Mestrado em Direito - Pontifícia Universidade Católica de São Paulo, São Paulo, 2009.

MENDES, Gilmar; PAIVA, Paulo. Politicas Publicas no Brasil. Uma abordagem institucional. São Paulo: Saraiva, 2017.

MONTEIRO, Jorge Viana. Legislatura e políticas públicas. Legislação, Caderno de Ciências de Legislação, n.2, dez. 1991.

MORAES, Alexandre de. Os 20 anos da Constituição da República Federativa do Brasil. São Paulo: Atlas S.A, 2009.

ONU. Organização das Nações Unidas. Convenção sobre os Direitos das Pessoas com Deficiência. 2006. Disponível em:

https://www.un.org/development/desa/disabilities/convention-on-the-rights-of-persons-withdisabilities.html. 
PINTO, Ronaldo Batista. Estatuto da Pessoa com Deficiência comentado. 2 ed. Bahia: Podivm, 2016.

RODRIGUES, Marta Maria Assumpção. Políticas Públicas. São Paulo: Publifolha, 2010.

SANTAGADA, Salvadore. Indicadores Sociais: uma primeira abordagem social e histórica.

Pensamento Plural. Pelotas, n. 1, p.113-142, jul/dez, 2007.

SANTOS, Marilia Lourido dos. Interpretação constitucional no controle judicial das políticas públicas. Porto Alegre: Sergio Antônio Fabris, 2006.

SARMENTO, Daniel. Dignidade da Pessoa Humana. Conteúdo, Trajetória e metodologia. 2 ed. Belo Horizonte: Fórum. 2016.

TAVARES, André Ramos. Curso de Direito Constitucional. 15 ed. São Paulo: Saraiva, 2017.

VITAL, Flávia Maria de Paiva. A Convenção sobre os Direitos da Pessoa com Deficiência Comentada. Brasília: Corde, 2008.

WLOCH, Fabrício; DEMARCHI, Clovis. Aspectos diferenciadores do direito nacional, internacional, plurinacional e transnacional. Revista do CEJUR/TJSC: Prestação Jurisdicional, Florianópolis, academia Judicial, v. 1, n. 3, p. 52-71, 2015. Disponível em: https://revistadocejur.tjsc.jus.br/cejur/article/view/100 